\title{
Early hCG addition to rFSH for ovarian stimulation in IVF provides better results and the cDNA copies of the $\mathrm{hCG}$ receptor may be an indicator of successful stimulation
}

Peter Drakakis*1, Dimitris Loutradis , Apostolos Beloukas², Vana Sypsa², Vasiliki Anastasiadou${ }^{1}$, George Kalofolias ${ }^{2}$, Helen Arabatzi ${ }^{1}$, Erasmia Kiapekou1 ${ }^{1}$, Konstantinos Stefanidis ${ }^{1}$, Dimitris Paraskevis ${ }^{2}$, Antonis Makrigiannakis ${ }^{3}$, Angelos Hatzakis ${ }^{2}$ and Aris Antsaklis ${ }^{1}$

Address: ${ }^{1}$ IVF Unit, Alexandra Hospital, 1st Department of Obstetrics and Gynecology, Athens University Medical School, Athens, Greece, ${ }^{2}$ Department of Hygiene, Epidemiology and Medical Statistics, Medical School, University of Athens, Athens, Greece and ${ }^{3}$ IVF Unit, Department of Obstetrics and Gynecology, Herakleion, Crete, Greece

Email: Peter Drakakis* - pdrakakis@hotmail.com; Dimitris Loutradis - loutradis@otenet.gr; Apostolos Beloukas - ampelouk@med.uoa.gr; Vana Sypsa - vsipsa@cc.uoa.gr; Vasiliki Anastasiadou - pakmar@otenet.gr; George Kalofolias - gkalofolias@hol.gr;

Helen Arabatzi - h.arabatzi@hotmail.com; Erasmia Kiapekou - ekiapek@otenet.gr; Konstantinos Stefanidis - konstef@hol.gr;

Dimitris Paraskevis - dparask@med.uoa.gr; Antonis Makrigiannakis - makrigia@med.uoc.gr; Angelos Hatzakis - ahatzak@med.uoa.gr;

Aris Antsaklis - aantsak@med.uoa.gr

* Corresponding author

Published: 13 October 2009

Reproductive Biology and Endocrinology 2009, 7:110 doi:10.1186/1477-7827-7-110

This article is available from: http://www.rbej.com/content/7/1/1/10

(C) 2009 Drakakis et al; licensee BioMed Central Ltd.

This is an Open Access article distributed under the terms of the Creative Commons Attribution License (http://creativecommons.org/licenses/by/2.0), which permits unrestricted use, distribution, and reproduction in any medium, provided the original work is properly cited.
Received: 19 April 2009

Accepted: 13 October 2009

\begin{abstract}
A simple, safe and cost-effective treatment protocol in ovarian stimulation is of great importance in IVF practice, especially in the case of previous unsuccessful attempts. $\mathrm{hCG}$ has been used as a substitute of LH because of the degree of homology between the two hormones. The main aim of this prospective randomized study was to determine, for the first time, whether low dose hCG added to rFSH for ovarian stimulation could produce better results compared to the addition of rLH in women entering IVF-ET, especially in those women that had previous IVF failures. An additional aim was to find an indicator that would allow us to follow-up ovarian stimulation and, possibly, modify it in order to achieve a better IVF outcome; and that indicator may be the cDNA copies of the LH/hCG receptor. Group A patients $(n=58)$ were administered $\mathrm{hCG}$ and Group $\mathrm{B}$ rLH $(\mathrm{n}=56)$ in addition to $\mathrm{rFSH}$ in the first days of ovarian stimulation. The number of follicles and oocytes and, most importantly, implantation and pregnancy rates were shown to be statistically significantly higher in the hCG group. This study has also determined, for the first time to our best knowledge, m-RNA for LH/hCG receptors in the lymphocytes of peripheral blood $40 \mathrm{~h}$ before ovum pick-up. cDNA levels of the hCG receptor after ovarian stimulation were significantly higher among women receiving $\mathrm{hCG}$ compared to those receiving $\mathrm{LH}$. In addition, higher levels were encountered among women with pregnancy compared to those without, although this was not statistically significant due to the small number of pregnancies. It seems that hCG permits a highly effective and more stable occupancy of $\mathrm{rLH} / \mathrm{hCG}$ receptors and gives more follicles and more oocytes. The determination of cDNA copies could be, in the future, a marker during ovulation induction protocols and of course a predictor for the outcome of ART in the special subgroup of patients with previous failures.
\end{abstract}




\section{Background}

The achievement of a simple, safe and cost-effective treatment protocol in controlled ovarian hyperstimulation $(\mathrm{COH})$ is of paramount importance to improve the quality of care in assisted reproduction. It is particularly important in the case of previous unsuccessful attempts. The midcycle gonadotrophin surge is a major event in the dynamics of ovulation. Rapidly increasing levels of luteinising hormone (LH) induce a number of key changes in both oocytes and follicular cells, which further modify the steroid and protein micro- and macroenvironment. These physiologic changes have a prominent role in the normal maturation of oocytes, the process of ovulation, and in subsequent fertilization and implantation [1].

Human chorionic gonadotrophin (hCG) has been used as a substitute for the LH surge because of the degree of homology between the two hormones [2]. hCG has a slower plasma metabolic clearance, which consists of a rapid phase in the first 5-9 $\mathrm{h}$ following intramuscular (IM) administration and a slower phase in the first 1-1.3 days after administration. Both LH and hCG are complex heterodimeric glycoproteins with a molecular weight of $\sim 30$ $\mathrm{K}$ for recombinant human LH (rLH) and $40 \mathrm{~K}$ for hCG. Their carbohydrate molecule is, though, different, thus leading possibly to a different affinity to the LH/hCG receptor and therefore to a differentiated function between LH and hCG. These two hormones have identical $\alpha$-subunits and a high cysteine content. Most importantly, they have the same natural function--to cause ovulation and support lutein cells. The major differences between the two hormones include the sequence of the $\beta$-subunit, the regulation of the secretion of the two hormones, the carbohydrate component and the pharmacokinetics of clearance of hCG as opposed to LH [3,4].

The LH/hCG receptor has an almost ubiquitous distribution in reproductive organs, thus suggesting that the actions of hCG might be more extensive than previously thought. Independently of follicular stimulation hormone (FSH), low-dose hCG can support development and maturation of larger ovarian follicles that have acquired granulosa cell LH/hCG receptors, potentially providing effective and safer ovulation induction regimens. Human chorionic gonadotrophin seems to be capable of improving uterine receptivity by enhancing endometrial quality and stromal fibroblast function. Furthermore, through its actions on insulin-like growth factor binding protein-1 and vascular endothelial growth factor, hCG might stimulate endometrial angiogenesis and growth and extend the implantation window, thus increasing pregnancy rates $[5,6]$.

Tailoring ovarian stimulation to the individual patient can be challenging because the ovarian response varies substantially between patients. Pharmacogenetics has emerged as a new area of research to improve the balance between desired and undesired actions of drugs, based upon the genetic predisposition of the individual patient.

The main aim of this study was to determine whether low dose hCG added to $\mathrm{rFSH}$ in regimens of ovarian stimulation could produce better results compared to the addition of rLH in women entering IVF-ET, especially in those women who had previous IVF failures. An additional aim was to find an indicator that would allow us to follow-up the ovarian stimulation and, possibly, predict a better IVF outcome in some women that may lead us to modify this stimulation; and that indicator may be the cDNA copies of the LH/hCG receptor.

\section{Methods Clinical study}

This prospective, randomized, pilot study was designed to compare the IVF outcome between two groups of patients, the first receiving $\mathrm{RLH}$ and the second hCG, both in addition to $\mathrm{rFSH}$ in patients undergoing ovarian stimulation for IVF-ET. All patients had 2-6 previous failed attempts.

All patients attended our Unit within a period of 12 months. They all were between 36 and 42 years old, had a body mass index (BMI) of 32 or less, a menstrual cycle lasting between 21 and 35 days, normal serum levels of $\mathrm{FSH}$, prolactin and TSH and a normal uterine cavity confirmed by hysteroscopy or hysterosalpingography. The causes for entering the program were: tubal factor, male factor, mild endometriosis (American Fertility Society classification stage I or II) [7] or unexplained infertility (with a history of at least 3 years of infertility). Patients hadn't had any other treatment with clomiphene citrate or gonadotrophins for at least 3 months before screening.

\section{Treatment protocol}

Group A patients (final $\mathrm{n}=58$, two cycles were cancelled) were administered hCG in addition to $\mathrm{rFSH}$ in the first days of ovarian stimulation, while Group B patients (final $\mathrm{n}=56$, four cycles were cancelled) were administered rLH in addition to rFSH. Based on findings by Filicori et al. [8], the dose of hCG was chosen to be 200 IU IM in Group A given for four days. The initial dose of rLH was chosen to be 200 IU based on pharmacokinetic data for LH given for four days also.

Commercially available GnRH-a (Suprefact, buserelin; Hoechst, Frankfurt, Germany) was self-administered subcutaneously (sc) into the thigh at a dose of $200 \mu \mathrm{g} /$ day, starting on the $2^{\text {nd }}$ day of the menstrual cycle and continuing until $24 \mathrm{~h}$ before the administration of hCG. Treatment with rFSH (Gonal-F; Serono, Geneva, Switzerland) was started on the third day of the menstrual cycle with $200 \mathrm{IU}$ and continued until the administration of hCG for ovulation induction. rFSH was administered once daily as 
a sc injection in the abdomen. In Group A patients, 200 IU of hCG were also administered sc for the first five days of ovarian stimulation. In Group B patients, 200 IU of rLH were administered sc for the same number of days. The ovarian response was monitored by ultrasound and measurement of plasma $\mathrm{E}_{2}$ levels, while the dose of $\mathrm{rFSH}$ was adjusted accordingly [9]. The maximum dose allowed was $450 \mathrm{IU} /$ day. The dose was reduced or discontinued if the patient was at risk of developing OHSS.

Ovulation was induced with 10000 IU of hCG within 24 $\mathrm{h}$ after the last rFSH and GnRH-a administration, preferably when all of the following criteria had been met: the largest follicle had reached a mean diameter of at least 18 $\mathrm{mm}$, at least one other follicle had a mean diameter of 16 $\mathrm{mm}$, and serum $\mathrm{E}_{2}$ levels were within an acceptable range for the number of follicles present. Oocytes were retrieved by regular follicle aspiration 34-38 h after hCG injection. From one to three embryos were replaced in the uterine cavity on day 2 or 3 after OPU.

\section{Luteal phase support}

Micronized progesterone $\left(\mathrm{P}_{4}\right)$ (Utrogestan, Faran, Greece) (200 mg three times daily) was administered by the vaginal route as luteal phase support, starting after oocyte collection. $\mathrm{P}_{4}$ treatment was continued up to menstruation or for at least the first 3 weeks if the patient became pregnant. Definition of pregnancy required a positive $\beta$ hCG test 14 days after embryo transfer. Definition of a clinical pregnancy required an endometrial gestational sac with a transvaginal ultrasound scan.

At the midluteal phase, careful abdominal ultrasound assessment was performed to record any signs of OHSS. The patient then was followed up, and the outcome (pregnancy or menstruation) was recorded.

\section{Method of assigning patients to study treatment}

The randomization scheme was prepared by a computer using Proc PLAN in SAS version 6.12 (SAS Institute Inc., Cary NC).

\section{Safety evaluation}

Safety was assessed through monitoring of all adverse events that occurred during the study, clinical assessment of local adverse reactions to injections, a questionnaire on clinical symptoms associated with OHSS at the time of hCG injection and at midluteal phase, $\mathrm{u} / \mathrm{s}$ of the ovaries and abdomen and monitoring of any pathologic changes in routine laboratory values.

\section{Statistical methods}

Patients were randomly assigned to rLH or hCG treatment according to balanced blocks of four subjects. Baseline characteristics of the patients were compared with the $\mathrm{t}$ test or the Wilcoxon's rank sum test, as appropriate. Com- parisons of pregnancy and other secondary outcomes between the two treatments were made by chi-square test or Wilcoxon's rank sum test, as appropriate. Multivariate logistic regression analysis was used to identify variables that are independent predictors of pregnancy outcome.

\section{IRB approval}

The study protocol was approved by the Institutional Review Board or Ethics Committee of Alexandra hospital before screening the first patient. Written informed consent was asked before study entry, with the understanding that consent could be withdrawn by the patient at any time without prejudice.

\section{LH/hCG receptors}

In this study we also examined the $\mathrm{LH} / \mathrm{hCG}$ receptor mRNA expression in the peripheral blood. The LH/hCG receptor mRNA expression was determined in the lymphocytes of peripheral blood by a novel molecular beacon based real-time PCR assay (RT-PCR) $40 \mathrm{~h}$ before ovum pick up.

\section{RNA extraction}

RNA extraction was performed as previously described [10]. Briefly, total RNA was extracted from the peripheral blood by employing a commercially available kit (RNA blood mini kit; Qiagen, Valencia, CA, USA) according to manufacturer's instructions. The use of RNase-free DNase I and carrier RNA, offered highly purified RNA.

\section{Reverse transcription-polymerase chain reaction (RT- PCR)}

Total RNA extracted from peripheral blood was used for cDNA synthesis by using Retroscript kit (Ambion, Austin, TX USA) according to manufacturer's instructions. Reverse transcription was followed by two rounds of nested PCR for LH/hCG mRNA and HPRT mRNA. Primer sequences used in both PCRs for LH/hCG mRNA amplification were designed with the Primer 3 program [11]. Primers pairs used for HPRT mRNA amplification have been described elsewhere [10]. All primers used were ordered from MWG Biotech (Table 1).

The first round PCR mastermix contained $5 \mu \mathrm{l}$ c-DNA in a total $50 \mu$ volume. $5 \mu \mathrm{l}$ of $10 \times$ PCR buffer, $1.5 \mathrm{mM}$ $\mathrm{MgCl}_{2} / \mathrm{l}, 0.2 \mu \mathrm{M}$ of $3^{\prime}$ and 5 ' outer primer, $0.2 \mathrm{mM}$ of each $\mathrm{dNTP} / \mathrm{l}$ and $1.5 \mathrm{u}$ Taq polymerase were used (Invitrogen Life Technologies). Cycling conditions were $94^{\circ} \mathrm{C}$ denaturation, the temperature of annealing specific for primers and $72^{\circ} \mathrm{C}$ extension, with each step lasting 1 minute. Final extraction was performed at $72^{\circ} \mathrm{C}$ for $10 \mathrm{~min}$. First PCR products were stored at $-20^{\circ} \mathrm{C}$.

For the second round of PCR $3 \mu$ of the primary product were added to $47 \mu$ freshly prepared mastermix containing PCR buffer, MgCl2, dNTPs, Taq polymerase and inner 
Table I: PCR Primers

\begin{tabular}{|c|c|c|c|c|c|}
\hline mRNA & $\begin{array}{c}\text { PCR primer } \\
\text { pair }\end{array}$ & $\begin{array}{c}\text { Primers } \\
5 '-3^{\prime}\end{array}$ & Sequence & $\begin{array}{c}\text { Annealing } \\
\text { Temperature } \\
\left({ }^{\circ} \mathrm{C}\right)\end{array}$ & $\begin{array}{c}\text { Product } \\
\text { size }\end{array}$ \\
\hline \multirow[t]{4}{*}{$\mathrm{LH} / \mathrm{hCG}$} & Outer pair & Forward & CAA TGT GAA AGC ACA GTA AGG A & 56 & \\
\hline & & Reverse & AGG CTA TGA GCA GCA GAT AGA G & 56 & 343 \\
\hline & Inner pair & Forward & GAA CTG AGT GGC TGG GAC TA & 56 & \\
\hline & & Reverse & GCA AAA GTC TGC AAA GGA GA & 56 & 249 \\
\hline \multirow[t]{4}{*}{ HPRT } & Outer pair & Forward & CTCCGCCTCСTCСTCTGCT & 50 & \\
\hline & & Reverse & GCCTGACCAAGGAAAGCAAAG & 50 & 528 \\
\hline & & Forward & GCCGGCTCCGTTATGGCG & 55 & \\
\hline & Inner pair & Reverse & AGCCCCCCTTGAGCACACAGA & 55 & 226 \\
\hline
\end{tabular}

primers in the same quantities as the first one. The second round of PCR was performed for 30 cycles in the same cycling conditions with annealing temperature specific for inner primers. Products were stored at $-20^{\circ} \mathrm{C}$.

The amplified products were analyzed by electrophoresis on $2 \%$ agarose gel containing ethidium bromide. $7 \mu \mathrm{l}$ of each PCR product run in parallel with a 100 bp DNA ladder (Invitrogen Life Technologies). (Figure 1)

The presence of LH/hCG receptor mRNA was investigated by nested PCR in peripheral blood of women undergoing IVF-ET. A specific band of 249 bps corresponding to the LH/hCG receptor was detected in all women examined. Furthermore the presence of HPRT mRNA in peripheral blood confirms the integrity of the RT-PCR process.

\section{Real-time PCR}

A real-time PCR assay was developed in order to quantitate LH/hCG receptor CDNA which was obtained with a

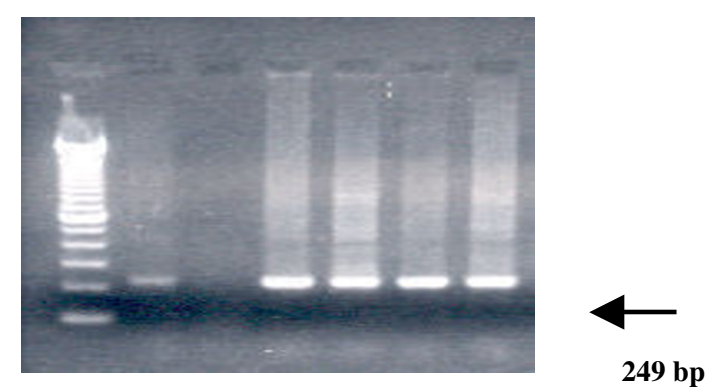

$\begin{array}{lllllll}\text { No of sample } & 1 & 2 & 3 & 4 & 5 & 6\end{array}$

Figure I

Gel electrophoresis of RT-PCR products for hCG-R (fragment 249) in peripheral blood of women undergoing IVF-ET. No I sample = positive control (cumulus cells), No 2 sample = negative control (distilled water), No 36 samples $=$ peripheral blood of women undergoing IVF-ET. reverse transcriptase (RT) assay from mRNA extracted from total blood.

Real-time PCR was optimized for human LH (hLH) receptor cDNA using a set of specific primers (inner set) and a molecular beacon probe labeled with a fluorescence dye for the amplification of hLH receptor. More specifically, hLH receptor primers and molecular beacon were newly designed targeting at a conserved region of gene sequence. The design of the primers and the molecular beacons was according to the standard requirements such as: (1) to avoid primer-beacon and primer-dimers and (2) the melting temperatures $\left(\mathrm{T}_{\mathrm{m}}\right)$ of the primers must be similar and at least $5-10^{\circ} \mathrm{C}$ lower than $\mathrm{T}_{\mathrm{m}} \mathrm{s}$ of the molecular beacons. The software tool used for the assessment of the $\mathrm{T}_{\mathrm{m}}$ calculations was from the Virtual Genome Centre http:// alces.med.umn.edu/VGC.html. The reaction mixture for RLT-PCR contained $2 \mu \mathrm{l}$ LightCycler FastStart Taq Reaction Mix 10× (Roche, Molecular Biochemicals, Mannheim, Germany), $6 \mathrm{mM} \mathrm{MgCl} 2,0.75 \mu \mathrm{M}$ primer hCG_for inner (forward) 5'-GAACTGAGTGGCTGGACTA-3', 0.75 $\mu \mathrm{M}$ primer hCG_rev inner (reverse) (Table 1), 5'GCAAAAGTCTGCAAAGGAGA-3', $0.017 \mu \mathrm{M}$ hLH_beacon 5'-GCCGGC CTGCTTACCCAAGACACCCCGATGTGCT GCCGGC-3' labeled with fluoresceine at the 5'-terminus and at their 3'-terminus bonded BHQ1, which is the quencher (Black Hole quencher 1). (MWG-BIOTECH Inc, U.K) (bold text indicates the complementary sequences forming the hairpin structure), 1.5 U FastStart Taq DNA polymerase (Roche, Molecular Biochemicals, Mannheim, Germany) and $1 \mathrm{U}$ of uracil-DNA glycosylase (Roche, Molecular Biochemicals, Mannheim, Germany) in a final volume reaction $20 \mu \mathrm{l}$. Ten microliters of DNA sample DNA were added in the LightCycler 2.0 capillaries containing $10 \mu \mathrm{l}$ of the reaction mix. The amplification conditions were optimized for LightCycler I as follows: one cycle of denaturation: $95^{\circ} \mathrm{C}$ for $10 \mathrm{~min}$ followed by 50 cycles of amplification at: $95^{\circ} \mathrm{C}$ for $10 \mathrm{~s}, 55^{\circ} \mathrm{C}$ for $10 \mathrm{~s}$ and at $72^{\circ} \mathrm{C}$ for $10 \mathrm{~s}$. Uracil-DNA glycosylase was used to eliminate PCR 'carry over' contaminations from previous PCR reactions. The cycle number during which the fluores- 
cence signal is above the background (CT) is proportional to the initial log concentration of the target DNA. For each run a standard curves was created in a 6-log range by 1:10 serial dilutions of hCG receptor's standard. The slope and correlation coefficient of each standard curve were calculated based on the average threshold cycle $\left(\mathrm{C}_{\mathrm{T}}\right)$ values measured in eight replicates for each dilution point ranging from $10^{6}$ to $10^{1}$ standard DNA templates. The PCR efficiency, E, corresponding to the experimentally derived dynamic range was computed as $\left(10^{-1 / s}-1\right) 100$, where $s$ is the slope of the standard curve generated. The concentration of hCG receptor at unknown extracted DNA samples quantified using the standard curve for external standard ds and was expressed as copies per $\mu \mathrm{l}$ of cDNA.

\section{Preparation of standard DNA}

hCG receptor amplicons were used as external standards after quantification in LightCycler 2.0 (Roche, Molecular Biochemicals, Mannheim, Germany) using PicoGreen dsDNA Quantification Kit (Molecular Probes). The concentration of hCG receptor amplicons was estimated according to standard curve calculated for serial dilutions of genomic DNA of known concentration (250-6.25 ng); Tenfold serial dilutions of the standards DNA with known DNA copy number were used for the generation of standard curves in amplification assays using molecular-beacon-based real-time PCR.

\section{Results}

This randomized, pilot clinical study was performed in a study period of 12 months between January 2007 and December 2007. A total of 120 patients were enrolled and randomized. Six women did not complete the study; two presented at risk for OHSS and four failed to develop a follicle with a mean diameter of at least $17 \mathrm{~mm}$. Of the remaining 114 women, 58 belonged to Group A (received hCG) and 56 to Group B (received rLH). All had at least one embryo transferred and all completed the midluteal phase assessment. The luteal phase was monitored in all patients who received hCG treatment.
The patients' characteristics prior to entering the program are summarized in Table 2. These characteristics did not differ between the two groups. The mean (SD) age of the patients was 36.4 (4.2) and 37.3 (1.8) for the hCG and LH group respectively $(\mathrm{p}=0.147)$. BMI was similar in the two groups (mean (SD): 22.7 (3.0) and 23.7 (3.4) for hCG and $\mathrm{LH}$ respectively, $\mathrm{p}=0.129)$. Mean $(\mathrm{SD})$ serum FSH was 8.4 (3.1) IU/L for the hCG group and 8.2 (2.8) IU/L for the LH group, mean (SD) serum LH was 6.1 (2.1) and 6.4 (3.0) IU/L respectively and mean (SD) PRL was 12.2 (6.2) and $10.3(4.7) \mathrm{ng} / \mathrm{ml}$ respectively for the two groups. The cause and duration of infertility, as well as the history of previous assisted reproductive techniques (ART) and non-ART pregnancies, were similar between the treatment groups. Uterine and ovarian sizes were comparable between the two groups (data not shown).

The IVF outcome in the two groups is presented in Table 3 . The mean (SD) number of days of ovarian stimulation was 10.8 (1.9) days for the hCG group and 11.1 (1.2) for the rLH group $(\mathrm{p}=0.240)$. The mean (SD) total rFSH dose per patient was 2940 (1231) IU (hCG treatment) and 4261 (1090) IU (rLH group) ( $<<0.001)$. Median $\left(25^{\text {th }}\right.$, $\left.75^{\text {th }}\right)$ serum E2 was $1888(1119,2118)$ and $720(530$, $1825) \mathrm{pg} / \mathrm{ml}$ for the hCG and LH group, respectively ( $\mathrm{p}=$ $0.003)$.

\section{Oocyte retrieval, fertilization and embryo cleavage}

The median number of follicles was 7.0 for hCG and 4 for LH $(\mathrm{p}<0.001)$ and the median number of oocytes retrieved per group was 6 for the hCG group and 3 for the LH one $(\mathrm{p}<0.001)$. No patient had more than 14 oocytes.

The majority of oocytes were in metaphase II $(75.0 \%$ for the hCG group and $66.7 \%$ for the rLH group, $\mathrm{p}=0.752$. The percentage of nuclear maturity was thus comparable between rLH and hCG

There was no significant difference in fertilization rate between the two treatment groups $(71.4 \%$ for hCG vs. $66.7 \%$ for $\mathrm{LH}, \mathrm{p}=0.317$ ).

Table 2: Baseline characteristics of patients according to treatment group

\begin{tabular}{|c|c|c|c|}
\hline & hCG $(\mathbf{N}=58)$ & LH $(\mathbf{N}=56)$ & $\mathbf{P}$ \\
\hline Age (years), mean (SD) & $36.4(4.2)$ & $37.3(1.8)$ & 0.147 \\
\hline BMI $\left(\mathrm{kg} / \mathrm{m}^{2}\right)$, mean $(\mathrm{SD})$ & $22.7(3.0)$ & $23.7(3.4)$ & 0.129 \\
\hline FSH (IU/L), mean (SD) & $8.4(3.1)$ & $8.2(2.8)$ & 0.683 \\
\hline LH (IU/L), mean (SD) & $6.1(2.1)$ & $6.4(3.0)$ & 0.623 \\
\hline PRL $(\mathrm{ng} / \mathrm{ml})$, mean $(\mathrm{SD})$ & $12.2(6.2)$ & $10.3(4.7)$ & 0.071 \\
\hline Years of Infertility (years), mean (SD) & $6.7(2.3)$ & $6.9(2.8)$ & 0.677 \\
\hline \multicolumn{4}{|l|}{ Cause of infertility, $\%$} \\
\hline Tubal Factor & 60 & 52 & 0.399 \\
\hline Male Factor & 37 & 39 & \\
\hline Other & 3 & 9 & \\
\hline
\end{tabular}


Table 3: Impact of treatment on intermediate outcomes

\begin{tabular}{|c|c|c|c|}
\hline & hCG & LH & $\mathbf{P}$ \\
\hline $\begin{array}{l}\text { Duration of stimulation (days) } \\
\text { mean (SD) }\end{array}$ & $\begin{array}{l}10.8 \\
(1.9)\end{array}$ & $\begin{array}{l}11.1 \\
(1.2)\end{array}$ & 0.240 \\
\hline $\begin{array}{l}\text { E2 on the day of } \mathrm{hCG}(\mathrm{pg} / \mathrm{ml}) \\
\text { median }\left(25^{\text {th }}-75^{\text {th }} \text { percentile) }\right.\end{array}$ & $\begin{array}{c}1888 \\
(1119,2118)\end{array}$ & $\begin{array}{c}720 \\
(530,1825)\end{array}$ & 0.003 \\
\hline $\begin{array}{l}\text { Total rFSH dose/patient } \\
\text { mean (SD) }\end{array}$ & $\begin{array}{c}2940 \\
(\mid 231)\end{array}$ & $\begin{array}{c}4261 \\
(1090)\end{array}$ & $<0.001$ \\
\hline $\begin{array}{l}\text { Number of follicles } \\
\text { median }\left(25^{\text {th }}-75^{\text {th }} \text { percentile }\right)\end{array}$ & $\begin{array}{c}7 \\
(5,9)\end{array}$ & $\begin{array}{c}4 \\
(3,7)\end{array}$ & $<0.001$ \\
\hline $\begin{array}{l}\text { Oocytes number } \\
\text { median }\left(25^{\text {th }}-75^{\text {th }} \text { percentile }\right)\end{array}$ & $\begin{array}{c}6 \\
(4,7)\end{array}$ & $\begin{array}{c}3 \\
(2,6)\end{array}$ & $<0.001$ \\
\hline $\begin{array}{l}\text { Proportion of mature oocytes }(\%) \\
\text { median }\left(25^{\text {th }}-75^{\text {th }} \text { percentile) }\right.\end{array}$ & $\begin{array}{c}75.0 \\
(57.1,100)\end{array}$ & $\begin{array}{c}66.7 \\
(66.7,100)\end{array}$ & 0.752 \\
\hline $\begin{array}{l}\text { Proportion of fertilized oocytes }(\%) \\
\text { median }\left(25^{\text {th }}-75^{\text {th }} \text { percentile) }\right.\end{array}$ & $\begin{array}{c}71.4 \\
(66.7,80.0)\end{array}$ & $\begin{array}{c}66.7 \\
(50.0,100)\end{array}$ & 0.317 \\
\hline $\begin{array}{l}\text { Number of transferable embryos } \\
\text { median }\left(25^{\text {th }}-75^{\text {th }} \text { percentile) }\right.\end{array}$ & $\begin{array}{c}4 \\
(2,4)\end{array}$ & $\begin{array}{c}2 \\
(1,3)\end{array}$ & $<0.001$ \\
\hline Proportion of patients with endometrium thickness $>8 \mathrm{~mm}(\%)$ & 80 & 69 & 0.190 \\
\hline Implantation rate $(\%)$ & 8.9 & 4.4 & 0.125 \\
\hline
\end{tabular}

The median number of transferable embryos was 4 for the hCG group and 2 for the rLH group $(\mathrm{p}<0.001)$.

The mean number of embryos transferred was $2.4 \pm 0.4$ for the hCG group and $2.5 \pm 0.4$ for the LH group ( $\mathrm{p}=$ 0.185 ) (Table 3 ).

Only embryos transferred during the study treatment cycle were considered in this analysis. All 114 patients had at least one embryo transferred. No more than three embryos were replaced in any patient.

\section{Endometrium}

The percentage of patients with endometrial thickness $>8$ $\mathrm{mm}$ was slightly higher in the hCG group ( $80 \%$ compared to $69 \%$; $\mathrm{p}=0.190$ ).

\section{Implantation rate}

Implantation rate (i.e. total pregnancies over the total number of transferred embryos) was $8.9 \%$ for the hCG group and $4.4 \%$ for the rLH group $\mathrm{p}=0.125$ (Table 3 ). No monozygotic were found in this study.

\section{Pregnancy rate}

In a univariate analysis, we assessed the effect of parameters such as age, BMI, basal serum hormone values and treatment with either hCG or LH on the achievement of pregnancy (Table 4). Treatment with hCG was found to be the only parameter that significantly increases pregnancy outcome expectation. A total of 16 clinical pregnancies $(27.6 \%)$ were recorded for hCG patients while 6 pregnancies $(10.7 \%)$ were recorded for the rLH group $(\mathrm{p}=0.022)$ (Table 4).
We also observe that (Table 5), after having adjusted for potential differences in age, BMI and baseline PRL, FSH, E2, women receiving hCG treatment have 3.6 times higher probability of achieving pregnancy compared with women receiving $\mathrm{LH}$ (95\% CI: 1.21-10.71, $\mathrm{p}=0.022)$.

\section{Ovarian hyperstimulation syndrome and adverse events}

The proportion of patients presenting with moderate OHSS [12] was similar in the two groups (about 12\%) and no serious adverse events were noted in any group.

\section{cDNA copies of the $h C G$ receptor}

cDNA levels after ovarian stimulation were significantly higher among women receiving hCG compared to women receiving LH (median levels: 25.3 copier per $\mu$ l of cDNA vs 6.8 copier per $\mu \mathrm{l}$ of cDNA, respectively, $\mathrm{p}=$ 0.012) (Table 6).

As far as prediction of pregnancy outcome by cDNA levels alone, higher levels are encountered among women with

Table 4: Univariate associations of patients' characteristics and treatment with pregnancy outcome

\begin{tabular}{lccc}
\hline & \multicolumn{2}{c}{ Pregnancy } & Yes \\
& & No & P \\
\hline Age, mean (SD) & $36.6(3.3)$ & $36.9(3.3)$ & 0.736 \\
BMI, mean (SD) & $23.1(3.8)$ & $23.2(3.1)$ & 0.934 \\
FSH, mean (SD) & $7.28(2.98)$ & $8.55(2.93)$ & 0.071 \\
PRL (SD) & $11.9(5.2)$ & $11.1(5.6)$ & 0.551 \\
LH (SD) & $6.29(2.53)$ & $6.24(2.60)$ & 0.944 \\
Treatment, n (\%) & & & \\
$\quad$ hCG & $16(27.6)$ & $42(72.4)$ & 0.022 \\
LH & $6(10.7)$ & $50(89.3)$ & \\
\end{tabular}


Table 5: Multiple logistic regression model for potential factors associated with increased probability of pregnancy

\begin{tabular}{lccc}
\hline & Odds ratio & $\mathbf{9 5 \%} \mathbf{C l}$ & $\mathbf{P}$ \\
\hline Age (/year) & 1.03 & $(0.00,1.20)$ & 0.735 \\
BMI & 1.02 & $(0.87,1.19)$ & 0.849 \\
Therapy hCG/LH & 3.60 & $(1.21,10.71)$ & 0.022 \\
PRL & 1.01 & $(0.92,1.11)$ & 0.865 \\
FSH & 0.84 & $(0.70,1.02)$ & 0.078 \\
E2 & 1.00 & $(1.00,1.00)$ & 0.746 \\
\hline
\end{tabular}

pregnancy compared to those without, this is not statistically significant though (Table 6).

\section{Discussion}

The necessary and the optimal dose as well as the time of LH administration in IVF cycles for the achievement of good quality oocytes and embryos has not yet been determined. The two-cell theory suggests that both FSH and LH are needed for normal follicular growth and maturation, but until now the main role has been attributed to FSH.

Studies in non-human primates have revealed that $\mathrm{LH}$ may act by increasing intraovarian androgens which promote FSH responsive granulosa cell function $[8,13]$ and, previous studies in humans have shown that LH acts synergistically with FSH to promote follicular growth [14]. However, no data exist on the potential clinical benefit of an "LH priming" effect as well as hCG.

Several studies have demonstrated that the administration of LH activity combined with FSH can exert significant actions on folliculogenesis. Still, reports on clinical data have been controversial. Late reports have employed $\mathrm{rLH}$ either before the administration of $\mathrm{rFSH}$ [6] or during the late part of ovarian stimulation $[8,15,16]$. A beneficial induction effect has been shown when rLH is administered before rFSH commenced in IVF cycles [6] but the authors suggested that the effect of supplementation with rLH on the clinical outcome needs to be clarified in the future. Our previous data with human luteinising hormone supplementation in the beginning of ovarian stim-

Table 6: cDNA levels according to treatment and pregnancy outcome

\begin{tabular}{|c|c|c|}
\hline & $\begin{array}{c}\text { CDNA (copies/ } \mu \mathrm{l}) \\
\text { median }\left(25^{\text {th }}-7^{\text {th }} \text { percentile) }\right.\end{array}$ & $\mathbf{P}$ \\
\hline \multicolumn{3}{|c|}{ Treatment, $\mathrm{n}(\%)$} \\
\hline hCG & $25.3(4.5,126.0)$ & 0.012 \\
\hline $\mathrm{LH}$ & $6.8(1.4,48.5)$ & \\
\hline \multicolumn{3}{|c|}{ Pregnancy, n(\%) } \\
\hline Yes & $14.2(4.5,72.9)$ & 0.687 \\
\hline No & $9.0(2.6,92.9)$ & \\
\hline
\end{tabular}

ulation showed a beneficiary effect [17] and this effect is with the early addition of hCG in this study.

The action of LH in preantral and small antral follicles was reported in literature to be limited [18]. However, granulosa cells express LH/hCG receptors and can be stimulated by both FSH and LH [19]. It has also been demonstrated by us that mRNA for the FSH and $\mathrm{LH}$ receptors exists in denuded oocytes as well as in preimplantation embryos at different stages, indicating a physiological role of $\mathrm{LH}$ in the oocyte maturation process and early embryonic development in the mouse and in humans $[10,11]$. Indeed, luteinising hormone activity can be provided in various ways: by human-derived LH contained in hMG, by recombinant LH, and by human-derived or recombinant hCG.

Our study has shown, for the first time to our best knowledge, that the administration of 200 IU of hCG daily, in addition to $\mathrm{rFSH}$, is a safe and possibly better alternative of human recombinant luteinising hormone supplementation for patients undergoing IVF/ICSI-ET. As stated before, other investigators have already used 200 IU of hCG in the last 3-4 days of ovarian stimulation in the long protocol $[8,15,16]$. In our study we used hCG supplementation during the first five days of ovarian stimulation in the short protocol. No negative impact of low-dose hCG administration was detected in patients receiving this treatment.

We also have to note that if we analyse the results with intention to treat, that is including the cases of patients that dropped treatment, we still have a statistically significant difference between pregnancy rates $(\mathrm{p}=0.018)$.

In most of the currently used ovarian stimulation protocols, serum LH is clearly suppressed through pituitary down regulation by GnRH agonists or antagonists. In the short protocol, LH is suppressed during the final days of the follicular growth (days 7-11). It seems, from our study, that the administration of 200 IU of hCG daily from days 3- 7 during the follicular growth permits a sufficient LH level in this period of ovulation induction. Our results have shown that with hCG we had lower number of gonadotrophin ampoules used, higher fertilization rate, higher and a better pregnancy rate with a tendency for a better implantation rate. In addition, the percentage of mature oocytes and the number and quality of embryos was comparable between rLH and hCG, thus showing that hCG, in the specific dose and way of administration, had no harmful effect on ovarian stimulation.

An explanation of the better ovulation profile in hCG treatment cycles could be the different isoform of hCG as compared to rLH. Differences in the carbohydrate moiety may make the molecule more sensitive to the binding 
receptor. In addition, the longer plasma half-life of hCG (half life of hCG is 33 hours while half life of rLH is 10-12 hours) results to a better and prolonged effect in the ovarian stimulation process $[3,20]$. It seems, therefore, that its longer plasma half-life and its greater potency (roughly six to eight times greater than that of LH) permit highly effective and more stable occupancy of the LH $\backslash$ hCG receptors. The fact that serum $\mathrm{E}_{2}$ levels in patients who received $\mathrm{rLH}$ were statistically significantly lower than in patients treated with hCG, shows that indeed the occupation of the $\mathrm{LH} / \mathrm{hCG}$ receptor in the $\mathrm{rLH}$-administered patients is less compared to the hCG stimulated patients.

The fact that single doses of rLH have a shorter effect than those of hCG is further substantiated by the performance of rLH in relation to the main characteristics of a natural LH surge as reported in the literature. The natural surge lasts for about 2 days $(49 \pm 9 \mathrm{~h})$ and is composed of an ascending phase (around $14 \mathrm{~h}$ ), a plateau (around $14 \mathrm{~h}$ ), and a descending phase (around $20 \mathrm{~h}$ ) [21]. LH serum levels, when measured by RIA, are about 10-20 times the basal LH levels. The surge profile obtained after a single injection of 5,000 IU hCG is very different from that of the natural LH surge. The main differences are the total duration (the hCG surge can last up to $120 \mathrm{~h}$ ) and the length of the descending phase. Previous publication suggested that using a conversion factor of 2.5, a dose of $12,500 \mathrm{IU}$ rLH would be as effective as 5,000 IU hCG in humans [22].

In terms of safety, this study shows that 200 IU of hCG is a well tolerated dose. Reported adverse effects are similar to those usually reported during stimulation cycles with rFSH and hMG. No negative impact of low-dose hCG administration was detected in patients receiving this treatment. Our study, thus, demonstrated that the administration of 200 IU of hCG daily can be applied as a supplement in patients with previous failed attempts during the short protocol in the first 5 days of superovulation.

This study has also determined, for the first time to our best knowledge, m-RNA for LH/hCG receptors in the lymphocytes of peripheral blood $40 \mathrm{~h}$ before ovum pick up. cDNA levels of the hCG receptor after ovarian stimulation were significantly higher among women receiving hCG compared to women receiving LH. In addition, higher levels were encountered among women with pregnancy compared to those without, although this was not statistically significant due to the small number of pregnancies. It seems that hCG permits a highly effective and more stable occupancy of rLH/hCG receptors and gives more follicles and more oocytes. This is due to the "down regulation" mechanism that is caused by the effect of the hormone on the receptors. As far as hCG and rLH are concerned for ovarian simulation, from this pilot study, it seems that the addition of hCG in the short protocol helps to improve the ovulation profile. It remains to be clarified, with the successive measurements of hormone in the blood during ovulation induction, which range of hCG in the blood relates with the optimum number of receptors.

The LH/hCG receptor has an almost ubiquitous distribution in reproductive organs, thus suggesting that the actions of hCG might be more extensive than previously considered [22,23]. The localization of the LH/hCG receptors in extragonadal reproductive tissues has suggested that hCG might exert additional actions and that these mechanisms could be exploited to enhance the efficacy of treatment used to manage infertile patients. The expression of LH/hCG receptors by theca cells and by granulosa cells has been well characterized $[23,24]$. Lowdose hCG can also be used instead of LH to permit in a more sustained manner the progression of folliculogenesis [5]. Moreover, the tendency, although not statistically significant for this sample number, for better implantation rate noted with hCG may reflect a more beneficial action to the endometrium compared to that of rLH administration since the number of embryos and their quality was the same.

However, the importance of this factor for the moment is not clearly established. The cDNA copies of LH/hCG receptor may act in concert with other environmental and genetic factors that could contribute to improve the ovulation protocols in the future. Also the determination of cDNA copies could be, in the future, a marker during ovulation induction protocols and of course a predictor for the outcome of ART in special subgroup of patients with previous failures. We are currently determining the variation of cDNA copies from the start of ovarian stimulation till luteal phase to see if there is a correlation between their level throughout ovarian stimulation and pregnancy outcome and if stimulation can be adjusted accordingly in order to provide a better outcome.

Finally, the results in this study are in agreement with the conclusion published recently by Filicori et al [5] stating that greater understanding of the physiologic role that hCG might play in human reproduction is beginning to suggest novel therapeutic applications for this traditional hormone of pregnancy.

\section{Conclusion}

Our study, as stated previously, demonstrated that the administration of 200 IU of hCG daily can be applied in addition to rFSH in patients with previous failed attempts during the short protocol in the first 5 days of superovulation increasing, thus, pregnancy rate.

This study has also determined, for the first time to our best knowledge, m-RNA for LH/hCG receptors in the lymphocytes of peripheral blood $40 \mathrm{~h}$ before ovum pick up. 
cDNA levels of the hCG receptor after ovarian stimulation were significantly higher among women receiving hCG compared to women receiving LH. In addition, higher levels were encountered among women with pregnancy compared to those without, although this was not statistically significant due to the small number of pregnancies. The determination of cDNA copies could be, in the future, a marker during ovulation induction protocols and of course a predictor for the outcome of ART in special subgroup of patients with previous failures.

\section{Competing interests}

The authors declare that they have no competing interests.

\section{Authors' contributions}

PD, DL, AM and AH made substantial contributions to conception and design and also to interpretation of data. $\mathrm{AB}, \mathrm{VS}, \mathrm{VA}, \mathrm{KG}, \mathrm{HA}, \mathrm{EK}, \mathrm{KS}$ and DP made substantial contributions to acquisition and analysis of data. PD was involved in drafting the manuscript. AA gave final approval of the version to be published. All authors read and approved the final manuscript.

\section{References}

I. Shoham Z, Schacter M, Loumaye E, Weissman A, MacNamee M, Insler $V$ : The luteinizing hormone surge--the final stage in ovulation induction: modern aspects of ovulation triggering. Fertil Steril 1995, 64:237-25I.

2. Chandrasekher YA, Hutchison JS, Zelinski-Wooten MB, Hess DL, Wolf DP, Stouffer RL: Initiation of periovulatory events in primate follicles using recombinant and native human luteinizing hormone to mimic the midcycle gonadotropin surge. J Clin Endocrinol Metab 1994, 79:298-306.

3. Yen SSC, Llenera G, Little B, Casper RF: Disappearance rate of endogenous luteinizing hormone and chorionic gonadotropin in man. J Clin Endocrinol Metab 1968, 28: I763-I767.

4. Weissman A, Lurie S, Zalel Y, Goldchmit R, Shoham Z: Human chorionic gonadotropin: pharmacokinetics of subcutaneous administration. Gynecol Endocrinol 1996, I0:273-276

5. Filicori M, Fazleabas AT, Huhtaniemi I, Licht P, Rao ChV, Tesarik J, Zygmunt M: Novel concepts of human chorionic gonadotropin: reproductive system interactions and potential in the management of infertility. Fertil Steril 2005, 84:275-284

6. Durnerin $\mathrm{Cl}$, Erb K, Fleming R, Hillier H, Hillier SG, Howles CM, Hugues JN, Lass A, Lyall H, Rasmussen P, Thong J, Traynor I, Westergaard L, Yates R, Luveris Pretreatment Group: Effects of recombinant LH treatment on folliculogenesis and responsiveness to FSH stimulation. Hum Reprod 2008, 23(2):42 I-6. Epub 2007 Dec 15

7. Revised American Fertility Society classification of endometriosis. Fertil Steril 1985, 43:35I-2.

8. Filicori M, Cognigni GE, Gamberini E, Parmegiani L, Troilo E, Roset B: Efficacy of low-dose human chorionic gonadotropin alone to complete controlled ovarian stimulation. Fertil Steril 2005, 84:394-40I.

9. Loutradis D, Drakakis P, Kallianidis K, Bletsa R, Milingos S, Makris N, Michalas S: The effect of the duration of GnRH-agonist down regulation before ovarian stimulation on the biological and clinical outcome after intracytoplasmic sperm injection. Eur J Obstet Gynecol Reprod Biol 1998, 80:25 I-255.

10. Patsoula E, Loutradis D, Drakakis P, Michalas L, Bletsa R, Michalas S: Messenger RNA expression for the follicle-stimulating hormone receptor and luteinizing hormone receptor in human oocytes and preimplantation-stage embryos. Fertil Steril 2003, 79: | 187- I 193.

II. Patsoula E, Loutradis D, Drakakis P, Kallianidis K, Bletsa R, Michalas $\mathrm{S}$ : Expression of mRNA for the LH and FSH receptors in mouse oocytes and preimplantation embryos. Reproduction 200 I, I 2 I :455-46 I.

12. Aboulghar MA, Mansour RT: Ovarian hyperstimulation syndrome: classifications and critical analysis of preventivemeasures. Hum Reprod Update 2003, 9(3):275-89.

13. Rao CV: Multiple novel roles of luteinising hormone. Fertil Steril 200I, 76: I097-II00.

14. Filicori M, Cognigni GE, Taraborrelli S, Spettoli D, Ciampaglia W, de Fatis $\mathrm{CT}$ : Luteinizing hormone activity supplementation enhances follicle stimulating hormone efficiency and improves ovulation induction outcome. J Clin Endocrinol Metab 1999, 84:2659-2663.

15. Nyboe Andersen A, Humaidan P, Fried G: T.H.E. Nordic rLH study group. Addition of rLH (Luveris) to rFSH during the final days of follicular maturation in IVF/ICSI treated patients. A Nordic randomized multicenter trial. Hum Reprod, Abstract Book, 22nd Annual Meeting of the ESHRE, Prague, Czech Republic 2006. Abstract No 0-138

16. Barrenetxea G, Agirregoikoa JA, Jiménez MR, de Larruzea AL, Ganzabal T, Carbonero K: Ovarian response and pregnancy outcome in poor-responder women: a randomized controlled trial on the effect of luteinizing hormone supplementation on in vitro fertilization cycles. Fertil Steril 2008, 89(3):546-53.

17. Drakakis P, Loutradis D, Kallianidis K, Liapi A, Milingos S, Makrigiannakis $A$, Dionyssiou-Asteriou A, Michalas S: Small doses of $\mathbf{L H}$ activity are needed early in ovarian stimulation for better quality oocytes in IVF-ET. Eur J Obstet Gynecol Reprod Biol 2005, | 2 | :77-80.

18. Zeleznik AJ, Hillier SG: The role of gonadotropins in the selection of the preovulatory follicle. Clin Obstet Gynecol 1984, 27:927-40.

19. Hillier SG, Whitelaw PF, Smyth CD, Hillier SG, Whitelaw PF, Smyth $C D$ : Follicular oestrogen synthesis: the 'two-cell, two-gonadotrophin' model revisited. Mol Cell Endocrinol 1994, 1 00:5 |-54.

20. Emperaire JC, Edwards RG: Time to revolutionize the triggering of ovulation. Reprod Biomed Online 2005, 9:80-83.

21. Emperaire JC, Parneix I, Ruffied A: Luteal phase defects following agonist-triggered ovulation: a patient-dependant response. Reprod Biomed Online 2004, 9:22-27.

22. Funaro A, Sapino A, Ferranti B, Horenstein AL, Castellano I, Bagni B, Garotta G, Malavasi F: Functional, structural, and distribution analysis of the chorionic gonadotropin receptor using murine monoclonal antibodies. J Clin Endocrinol Metab 2003 , 88:5537-5546.

23. Menon KM, Munshi UM, Clouser CL, Nair AK: Regulation of luteinizing hormone/human chorionic gonadotropin receptor expression; A perspective. Biol Reprod 2004, 70:86I-866.

24. Minegishi T, Tano M, Abe Y, Nakamura K, Ibuki Y, Miyamoto K: Expression of luteinizing hormone/human chorionic gonadotrophin (LH/HCG) receptor mRNA in the human ovary. Mol Hum Reprod 1997, 3(2): 101-107.

\section{Publish with Bio Med Central and every scientist can read your work free of charge}

"BioMed Central will be the most significant development for disseminating the results of biomedical research in our lifetime. "

Sir Paul Nurse, Cancer Research UK

Your research papers will be:

- available free of charge to the entire biomedical community

- peer reviewed and published immediately upon acceptance

- cited in PubMed and archived on PubMed Central

- yours - you keep the copyright 